\title{
Visible LED-Based Instrumentation for Photometric Determination of Electroosmotic Flow in Microchannels
}

\author{
José Alberto Fracassi da Silva, ${ }^{*, a, b}$ Ariane Deblire, ${ }^{a}$ Dosil P. de Jesus ${ }^{a b}$ and \\ Wendell Karlos T. Coltro ${ }^{b, c}$ \\ anstituto de Química, Universidade Estadual de Campinas, 13083-970 Campinas-SP, Brazil \\ ${ }^{b}$ Instituto Nacional de Ciência e Tecnologia em Bioanalítica (INCTBio), Campinas-SP, Brazil \\ 'Instituto de Química, Universidade Federal de Goiás, 74001-970 Goiânia-GO, Brazil
}

\begin{abstract}
A instrumentação para a determinação fotométrica do fluxo eletrosmótico (EOF) em dispositivos microfluídicos é descrita neste trabalho. A instrumentação é baseada em componentes acessíveis e consiste em um microscópio trinocular e no fotodiodo integrado OPT101. Um diodo emissor de luz (LED) de alta intensidade foi utilizado como fonte de radiação. Para as determinações foram utilizadas soluções aquosas dos corantes azul patente $\mathrm{V}$ e azul de metileno. O sistema foi utilizado no monitoramento do EOF em microdispositivos de poli(dimetilsiloxano) (PDMS) e híbridos de toner/vidro. As mobilidades do EOF determinadas em $\mathrm{pH} 7,0$ foram $(5,75 \pm 0,01) 10^{-4} \mathrm{~cm}^{2} \mathrm{~V}^{-1} \mathrm{~s}^{-1}$ e $(3,2 \pm 0,1) 10^{-4} \mathrm{~cm}^{2} \mathrm{~V}^{-1} \mathrm{~s}^{-1}$ para os dispositivos de toner/vidro e PDMS, respectivamente. Medidas reprodutíveis foram obtidas em todos os experimentos, levando a uma alta precisão na determinação. O método proposto foi comparado com o método tradicional de determinação do EOF que envolve a medida da corrente nos microcanais.
\end{abstract}

An instrumental setup for electroosmotic flow (EOF) determination in microfluidic devices is described. The system is based on a trinocular microscope and an integrated photodiode OPT101. The radiation was provided by a high-intensity white LED. For the determinations, patent blue $\mathrm{V}$ and methylene blue aqueous solutions were used. The setup was applied for EOF monitoring in hybrid toner/glass and PDMS microchips. For the toner/glass device, the EOF mobility was determined to be $(5.75 \pm 0.01) 10^{-4} \mathrm{~cm}^{2} \mathrm{~V}^{-1} \mathrm{~s}^{-1}$ at $\mathrm{pH} 7.0$. For PDMS devices the measured EOF mobility was (3.2 \pm 0.1$) 10^{-4} \mathrm{~cm}^{2} \mathrm{~V}^{-1} \mathrm{~s}^{-1}$. Reproducible measurements were obtained in all experiments, which produced results with small errors. The proposed method was compared to the conventional current monitoring method.

Keywords: electroosmotic flow, $\mu$ TAS, Lab-on-a-chip, photometric methods, microfluidic devices

\section{Introduction}

Electroosmotic flow (EOF) is the movement of solvent molecules caused by an applied voltage in a capillary system. EOF plays an essential role in electromigration separation techniques, such as capillary zone electrophoresis (CZE or free solution capillary electrophoresis, FSCE) or microchip electrophoresis, ${ }^{1}$ since the velocity of the ions is influenced by the magnitude of the EOF. As an example, both positively and negatively charged species can be simultaneously analyzed due to the EOF. Moreover, the EOF magnitude

*e-mail: fracassi@iqm.unicamp.br could bring some information about the condition of the surface of the capillary or microchannel wall. In particular, the knowledge about the surface charge density (including not only the EOF magnitude but also the zeta potential) can be of paramount importance for preventing adsorption of analyte to the wall.

It is well accepted that EOF has its origin on the unbalanced charge distribution in the region closer to the capillary/microchannel wall, the so called electrical double layer (EDL). More precisely, the flow is caused by the movement of excess ions in the diffuse portion of the EDL. Mathematical treatment of the EOF combines the Newton Law applied to the viscous fluids and Poisson's charge distribution to give the velocity of the $\operatorname{EOF}\left(\mathrm{v}_{x}\right): 2,3$ 
$v_{\mathrm{x}}=\frac{\varepsilon \mathrm{E}\left(\varphi_{\mathrm{x}}-\zeta\right)}{\eta}$

where $\varepsilon$ is the relative permittivity of the solution inside the microchannel, $\mathrm{E}$ is the magnitude of the electric field strength, $\zeta$ is the zeta potential (or electrokinetic potential), $\phi_{x}$ is the potential on the plane at a distance $x$ from the microchannel wall, and $\eta$ is the dynamic viscosity of the solution in the region of the EDL.

This equation reveals that the velocity of the $\operatorname{EOF}\left(v_{\mathrm{eo}}\right)$ is constant for distances greater than 3 or 4 times the EDL thickness, since the potential $\phi_{\mathrm{x}}$ approaches to zero:

$v_{\mathrm{eo}}=-\frac{\varepsilon \mathrm{E} \zeta}{\eta}$

The EOF mobility, $\mu_{\mathrm{eo}}$, is the ratio between the EOF velocity and the electric field strength:

$\frac{v_{\mathrm{eo}}}{\mathrm{E}}=\mu_{\mathrm{eo}}=-\frac{\varepsilon \zeta}{\eta}$

According to these equations, it is clear that the EOF mobility depends on both the capillary/microchannel wall conditions and solution properties, such as viscosity and ionic strength of the background electrolyte (BGE). Regarding to the microchannel wall, parameters affecting the charge of the wall (e.g., ionizable groups in the surface) will strongly influence the zeta potential, and consequently the EOF mobility. The monitoring of the EOF is of great importance, since it is an indirect measurement of the surface condition and because it significantly influences the electrophoresis performance. Additionally, values for the zeta potential can be obtained from EOF data. ${ }^{4,5}$

Traditionally, EOF can be measured by monitoring a neutral species moving on the microchannel through the application of an electric field. This method depends on the physicochemical properties of the species, such as high molar absorptivity, electroactivity, fluorescence, and so on. Alternative methods for the EOF monitoring employ photobleaching of molecules, ${ }^{6-8}$ conductometry, ${ }^{9}$ indirect amperometry, ${ }^{10,11}$ indirect fluorescence, ${ }^{12}$ frontal analysis, ${ }^{13}$ and the creation of different temperature zones (thermal marks). ${ }^{14,15}$

Because of its instrumental simplicity, the currentmonitoring method is also very popular. ${ }^{16-21}$ In this method, the microchannel is filled with an electrolyte (for example, $10 \mathrm{mmol} \mathrm{L}^{-1}$ phosphate buffer) and the solution in one of the reservoirs is replaced by a more diluted electrolyte (for example, $9.0 \mathrm{mmol} \mathrm{L}^{-1}$ phosphate buffer). The high voltage is applied and the resulting current is monitored. In this case, using a proper polarity, the diluted solution gets into the microchannel with the velocity of the EOF, augmenting the channel resistance and reducing the current. After the complete replacement of the solution in the channel - by the EOF pumping - the current stabilizes and the time required for this stabilization is measured. The mobility of the EOF $\left(\mathrm{cm}^{2} \mathrm{~V}^{-1} \mathrm{~s}^{-1}\right)$ can be obtained by the following equation:

$\mu_{\mathrm{eo}}=\frac{1 \mathrm{~L}}{\mathrm{Vt}_{\mathrm{eo}}}$

where $\mathrm{L}$ is the total length of the channel $(\mathrm{cm}), \mathrm{V}$ is the applied voltage $(\mathrm{V})$, and $\mathrm{t}_{\mathrm{eo}}$ is the time required for the current stabilization (s). When other detector, such as photometric, is used for the determination, the effective length (1) must be considered, but for the case of current method 1 equals $\mathrm{L}$.

Although the current monitoring method is very simple and requires no additional instrumentation, in some cases is quite difficult to visualize the current stabilization. This is due to the dilution of the replenishment solution when it reaches the opposite reservoir of the device. Depending on the geometry of the microchannel and reservoir, this dilution can introduce considerable errors in the EOF determination. Additionally, Pittman and co-workers ${ }^{6}$ reported that the current monitoring method can cause changes in the EOF as high as $41 \%$ in a single experiment.

To overcome this problem, we propose in this work an alternative method for EOF monitoring based on the same principle of the refilling the channel employed in the current monitoring method but making use of the change on the transmittance of visible radiation of an electrolytic solution containing a dye, instead of measuring the electrical current. This new method comprises a simple and accessible instrumentation and was applied for EOF measurement in glass/toner and poly(dimethylsiloxane) (PDMS) microdevices.

\section{Experimental}

\section{Reagents and solutions}

All solutions were prepared using deionized water from a Milli-Q purification system (Millipore, Bedford, MA, USA) with resistivity greater than $18 \mathrm{M} \Omega \mathrm{cm}$. All chemicals were of analytical grade and used as received.

Sodium dihydrogen phosphate, disodium hydrogen phosphate, and methylene blue were purchased from Synth (LabSynth, Diadema, SP, Brazil). The dye patent blue V was gently donated by Sensient Colors Brasil Ltda (Santana de Parnaiba, SP, Brazil). Silastic ${ }^{\circledR}$ T-2 Translucent Base (Dow Corning, Midland, MI, USA) was used in the 
preparation of PDMS microchips in the proportion prepolymer/catalyst of $10: 1(\mathrm{~m} / \mathrm{m})$.

Stock solutions of patent blue $\mathrm{V}$ were prepared in the concentrations 0.08 and $4.0 \mathrm{~g} \mathrm{~L}^{-1}$. Stock solutions of methylene blue were prepared in $20 \mathrm{mmol} \mathrm{L}^{-1}$ phosphate buffer, $\mathrm{pH} 6.0$, in the concentrations 0.1 and $1.0 \mathrm{mmol} \mathrm{L}^{-1}$.

\section{Microfluidic devices fabrication}

The feasibility of the proposed method was evaluated using glass/toner and PDMS microfluidic devices. Glass/ toner microchips were produced according to fabrication technology described by Do Lago et al. ${ }^{22}$ PDMS microchips were fabricated using the well-established soft-lithographic protocol, where a master is produced and microchannels are replicated via direct polymerization over the master. ${ }^{23}$ The high-relief master was fabricated in the Laboratory of Microfabrication at the National Synchrotron Light Source (LNLS, Campinas, SP, Brazil) using standard photolithographic protocols. In this case, metallic nickel was electrodeposited onto an alumina substrate using UVLIGA process. ${ }^{23}$

In this work, glass/toner microchannels were produced with $100 \mu \mathrm{m}$ width, $12 \mu \mathrm{m}$ deep, and $6 \mathrm{~cm}$ long. In addition, PDMS microchannels were fabricated with $100 \mu \mathrm{m}$ width, $60 \mu \mathrm{m}$ deep, and $4 \mathrm{~cm}$ long. The photometric detector was placed at 4.3 and $2.7 \mathrm{~cm}$ from the inlet reservoir for glass/ toner and PDMS microchips, respectively.

\section{Instrumentation}

Figure 1 shows the instrumental setup for EOF photometric measurements. A photograph of the instrumental setup can be found in the Supplementary Information. The system was built with a trinocular microscope (model Q-709t, Quimis, Diadema, SP, Brazil). A high-intensity white LED was used as light source, supplied by $5.5 \mathrm{~V}$ using dual-channel, adjustable power supply (model MPC-303D, Minipa, São Paulo, SP, Brazil). A $580 \mathrm{~nm}$ cut-off high-pass optical filter was used, but the use of a high-intensity red LED can substitute the white LED. The 100X objective was used throughout this work. A monolithic photodiode and amplifier OPT101 (Texas Instruments, Dallas, TX, USA) as well as the electronic circuitry (Supplementary Information) were cased in a plastic box and the ensemble was adapted to the microscope using a copper tube..$^{22}$ The output of the amplifier was interfaced to a Pentium $133 \mathrm{MHz}$ microcomputer through a PCL-711 interface card (Advantech, Taipei, Taiwan). The data acquisition program was written in Delphi 5.0 (Borland). A model TCH 1500-
100 mA high voltage power supply (Tectrol, São Paulo, SP, Brazil) was used in the experiments. The voltage was set to $1500 \mathrm{~V}$ and $1000 \mathrm{~V}$ for glass/toner and PDMS microchips, respectively, and applied to the microchannels by using stainless steel needles. The data acquisition of the current in the microchannels and the control of the applied high voltage were also included in the control software.

All experiments were carried out at room temperature $\left(25 \pm 1^{\circ} \mathrm{C}\right)$.

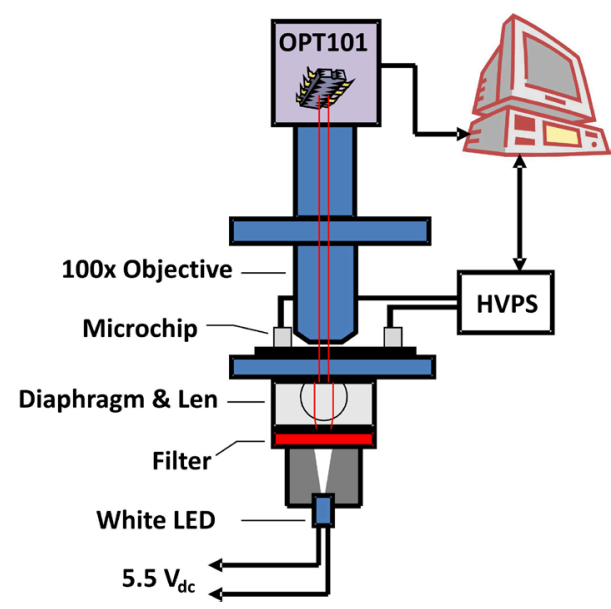

Figure 1. Scheme of the instrumental setup. HVPS stands for high-voltage power supply.

\section{Results and Discussion}

The method for determination of the EOF proposed is depicted in Figure 2. First, channel and reservoirs are filled with diluted dye solution (Figure 2a). Then, diluted solution in the inlet reservoir is replaced by more concentrated dye solution (Figure 2b). The high voltage is turned on and the solution is moved toward the detector with the velocity of EOF (Figure 2c). In this case a cathodic EOF is assumed. By recording the output of the photometric detector, is possible to measure the time $\left(t_{\mathrm{eo}}\right)$ the concentrated solution takes to reach the detector and calculate $\mu_{\mathrm{eo}}$ by using equation 4 .

When preparing the instrumental conditions for the EOF determination, one must note that the focal plane is different for the ocular lens and for the photodiode (Supplementary Information). For this reason, the oculars were used preliminarily only to positioning the objective on the region determined by the microchannel walls. Next, the focus is adjusted through the maximization of the OPT101 output signal, since its absolute value is proportional to the intensity of radiation that reaches the photoactive area. If focus adjust is avoided, small variations of the OPT101 output is observed, making difficult the determination of $\mathrm{t}_{\mathrm{e} 0}$.

As exemplified in Figure 2, by changing the solution on the inlet reservoir and applying the high voltage, the 


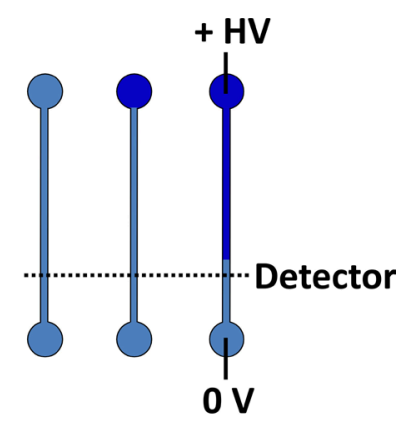

(a) (b) (c)

Figure 2. Scheme of the EOF determination. (a) The channel is filled with a diluted dye solution; (b) Diluted solution in one reservoir is replaced by the concentrated dye solution; (c) High voltage (HV) power supply is turned on. In this scheme a cathodic EOF is generated.

solution inside the microchannel is replaced and the velocity of replacement is governed by the velocity of the EOF, since there are the same ions in both diluted and concentrated zones. If a concentrated solution is placed on the inlet reservoir it is expected a reduction in the intensity of radiation reaching the detector, dropping the OPT101 output signal (Figure 3). Simultaneously, as the concentrated solution enters the microchannel, the channel electrical resistance is dropped, increasing the electrical current. The opposite process (filling the channel with a concentrated solution) is also applicable, but in this case a rise in the output of OPT101 and a current reduction is achieved.

Figure 3 shows typical experimental results for EOF determination, as exemplified in Figure 1, using 0.08 and $4.0 \mathrm{mg} \mathrm{L}^{-1}$ patent blue V dye solutions. Simultaneous acquisition of current and photodiode output was performed and the graph shows three consecutive runs. Approximately, a difference of $200 \mathrm{mV}$ in the OPT101 output was obtained in the transition of the diluted to concentrated solution boundary. It can be observed that the current deviates in a higher extend and the transition is not so sharp when compared to the photodiode output signal. In fact, the repeatability of the photometric detector is impressive. One of the problems associated with the current monitoring is how to determine the exact point in the graph where the current stabilizes. We tried to develop methods for the analysis of these curves in order to improve the accuracy of the determinations. For example, the first derivative of the current data was evaluated in order to determine the ending point, but even this mathematical data treatment did not eliminate the subjectivity of the determination by using the current monitoring method. To sum up, smoother the transition in the current-time curves more difficult and uncertain is the EOF determination. The mobility of the EOF obtained for this glass/toner microchip was $(5.75 \pm 0.01) 10^{-4} \mathrm{~cm}^{2} \mathrm{~V}^{-1} \mathrm{~s}^{-1}$, measured with solutions of patent blue $\mathrm{V}$ at $\mathrm{pH} 7.0$ and using the described conditions. This value is higher than $3.510^{-4} \mathrm{~cm}^{2} \mathrm{~V}^{-1} \mathrm{~s}^{-1}$ obtained in a previous work, ${ }^{22}$ but one must consider differences in the experimental conditions, such as ionic strength and temperature. Most important, the order of magnitude of the measured EOF is in agreement to glass/toner surfaces. ${ }^{22}$ The EOF measurement obtained simultaneously using the current method was $(4.2 \pm 0.1) 10^{-4} \mathrm{~cm}^{2} \mathrm{~V}^{-1} \mathrm{~s}^{-1}$. The difference could be attributed to small variations in the position of the photometric detector and difficulties in determine the exact $\mathrm{t}_{\mathrm{eo}}$ in the current versus time graph.

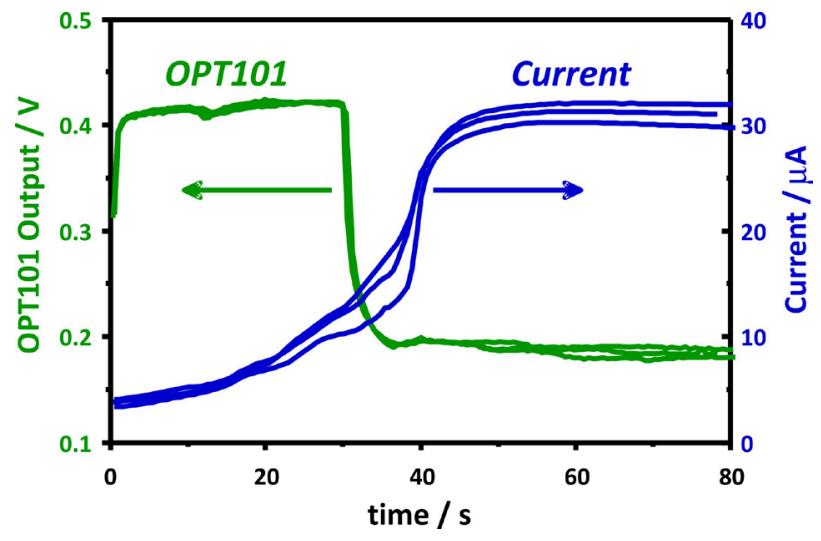

Figure 3. Results for the EOF monitoring in hybrid toner/glass microchip using the photometric method (OPT101) and the current method. Conditions: High voltage: $1500 \mathrm{~V}$; Dye: 0.08 and $4.0 \mathrm{~g} \mathrm{~L}^{-1}$ patent blue $\mathrm{V}$ at $\mathrm{pH}$ 7.0.

The LED-based photometric method was also applied in the determination of the EOF in PDMS microchips. Experiments were also carried out with methylene blue at concentrations 0.1 and $1.0 \mathrm{mmol} \mathrm{L}^{-1}$ in $20 \mathrm{mmol} \mathrm{L}^{-1}$ phosphate buffer, $\mathrm{pH} 6.0$ and representative results can be seen in Figure 4. In this case, the OPT101 supplied less than $10 \mathrm{mV}$ in the output for transition from the diluted to concentrated solutions of methylene blue. This could be due to the spurious light transmitted outside the channel, since the whole microchip is transparent, in contrast of glass/toner microchips where the toner layers block the LED radiation outside the channel. In general, it was more difficult to adjust the focus for PDMS microchips, because the cover layer was thick ( $c a .2 \mathrm{~mm}$ ). Nevertheless, even in this unfavorable case it was possible to visualize the output transition. The determined EOF for this PDMS microchip at set conditions was $(3.2 \pm 0.1) 10^{-4} \mathrm{~cm}^{2} \mathrm{~V}^{-1} \mathrm{~s}^{-1}$.

\section{Conclusions}

The proposed method for the EOF monitoring presented some advantages when compared to the current method. Sharp transitions were observed in all experiments, which 


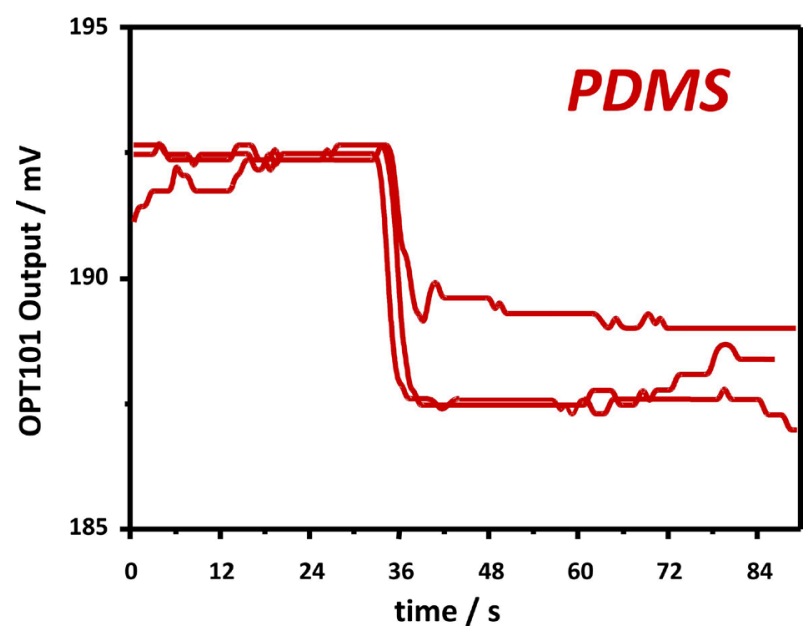

Figure 4. Results for the EOF monitoring in PDMS microchip using the photometric method (OPT101) and the current method. Conditions: High voltage: $1000 \mathrm{~V}$; Dye: 0.1 and $1.0 \mathrm{mmol} \mathrm{L}^{-1}$ methylene blue in $20 \mathrm{mmol} \mathrm{L}^{-1}$ phosphate buffer, pH 6.0.

allow monitoring the mobility of the EOF with small errors. Also, the photometric method does not depend on the absolute value of the channel current, which could impose some limitations to the current monitoring method. So, experimental conditions closer to that commonly used in electromigration techniques can be set. The positioning of the photometric detector could be improved using align marks during the process of fabrication of the devices, which could improve the reproducibility and accuracy of the EOF determination. The instrumentation is of low cost and safe, since it uses visible LED radiation. Unfortunately, the method cannot be applied to substrates non-transparent to radiation. Using the instrumentation proposed, we could successfully determine the EOF magnitude for hybrid toner/glass and PDMS microdevices. Also, there is the possibility of the use of neutral dyes EOF markers that could improve the measurements, since they would not introduce variations in EOF due to changes in the ionic strength.

\section{Supplementary Information}

Supplementary data are available free of charge at http://jbcs.sbq.org.br, as PDF file.

\section{Acknowledgments}

Authors thank Fundação de Amparo à Pesquisa do Estado de São Paulo (FAPESP) and Conselho Nacional de Desenvolvimento Científico e Tecnológico (CNPq) for financial support. Laboratório Nacional de Luz Síncrotron (LNLS), for using their facilities, and Dr. Carol H. Collins, for manuscript language revision, are also acknowledged.

\section{References}

1. da Silva, J. A. F.; Coltro, W. K. T.; Carrilho, E.; Tavares, M. F. M.; Quim. Nova 2007, 30, 740.

2. Tavares, M. F. M.; Quim. Nova 1996, 19, 176.

3. Oldham, K. B.; Myland, J. C.; Fundamentals of Electrochemical Science, Academic Press: San Diego, CA, USA, 1994, ch. 9.

4. Kirby, B. J.; Hasselbrink Jr., E. F.; Electrophoresis 2004, 25 , 187.

5. Kirby, B. J.; Hasselbrink Jr., E. F.; Electrophoresis 2004, $25,203$.

6. Pittman, J. L.; Henry, C. S.; Gilman, S. D.; Anal. Chem. 2003, 75,361 .

7. Pittman, J. L.; Schrum, K. F.; Gilman, S. D.; Analyst 2001, 126, 1240.

8. Schrum, K. F.; Lancaster III, J. M.; Johnston, S. E.; Gilman, S. D.; Anal Chem. 2000, 72, 4317.

9. Liu, Y.; Wipf, D. O.; Henry, C. S.; Analyst 2001, 126, 1248.

10. Wang, W.; Zhao, L.; Jiang, L.-P.; Zhang, J.-R.; Zhu, J.-J.; Chen, H.-C.; Electrophoresis 2006, 27, 5132.

11. Wang, W.; Zhao, L.; Zhang, J.-R.; Zhu, J.-J.; J. Chromatogr., A 2007, 1142, 209.

12. Chen, R.; Guo, H.; Shen, Y.; Hu, Y.; Sun, Y.; Sens. Actuators, A 2006, 114, 1100.

13. Shakalisava, Y.; Poitevin, M.; Viovy, J.-L.; Descroix, S.; J. Chromatogr., A 2009, 1216, 1030.

14. Saito, R. M.; Neves, C. A.; Lopes, F. S.; Blanes, L.; Brito-Neto, J. G. A.; Do Lago, C. L.; Anal. Chem. 2007, 79, 215.

15. Seiman, A.; Vaher, M.; Kaljurand, M.; J. Chromatogr., A 2008 , 1189, 266.

16. Huang, X.; Gordon, M. J.; Zare, R. N.; Anal. Chem. 1988, 60, 1837.

17. Locascio, L. E.; Perso, C. E.; Lee, C. S.; J. Chromatogr., A 1999, 857, 275.

18. Gaudioso, J.; Craighead, H. G.; J. Chromatogr., A 2002, 971, 249.

19. Wang, C.; Wong, T. N.; Yang, C.; Ooi, K. T.; Int. J. Heat Mass Transfer 2007, 50, 3115.

20. Almutairi, Z. A.; Glawdel, T.; Ren, C. L.; Johnson, D. A.; Microfluid Nanofluid 2009, 6, 241.

21. Wang, W.; Wu, W.; Zhou, F.; Zhang, J.-R.; Miao, Q.; Zhu, J.-J.; Chromatographia 2009, 69, 897.

22. Do Lago, C. L.; Neves, C. A.; de Jesus, D. P.; da Silva, H. D. T.; Brito-Neto, J. G. A.; da Silva, J. A. F.; Electrophoresis 2004, 25,3825

23. Coltro, W. K. T.; Piccin, E.; Carrilho, E.; de Jesus, D. P.; da Silva, J. A. F.; da Silva, H. D. T.; Do Lago, C. L.; Quim. Nova 2007, 30, 1986.

Submitted: June 25, 2010

Published online: January 20, 2011

FAPESP has sponsored the publication of this article. 


\section{Supplementary Information}

\section{Visible LED-Based Instrumentation for Photometric Determination of Electroosmotic Flow in Microchannels}

José Alberto Fracassi da Silva, ${ }^{*, a, b}$ Ariane Deblire, ${ }^{a}$ Dosil P. de Jesus ${ }^{a b}$ and

Wendell Karlos T. Coltro ${ }^{b, c}$

Instituto de Química, Universidade Estadual de Campinas, 13083-970 Campinas-SP, Brazil

${ }^{b}$ Instituto Nacional de Ciência e Tecnologia em Bioanalítica (INCTBio), Campinas-SP, Brazil

'Instituto de Química, Universidade Federal de Goiás, 74001-970 Goiânia-GO, Brazil

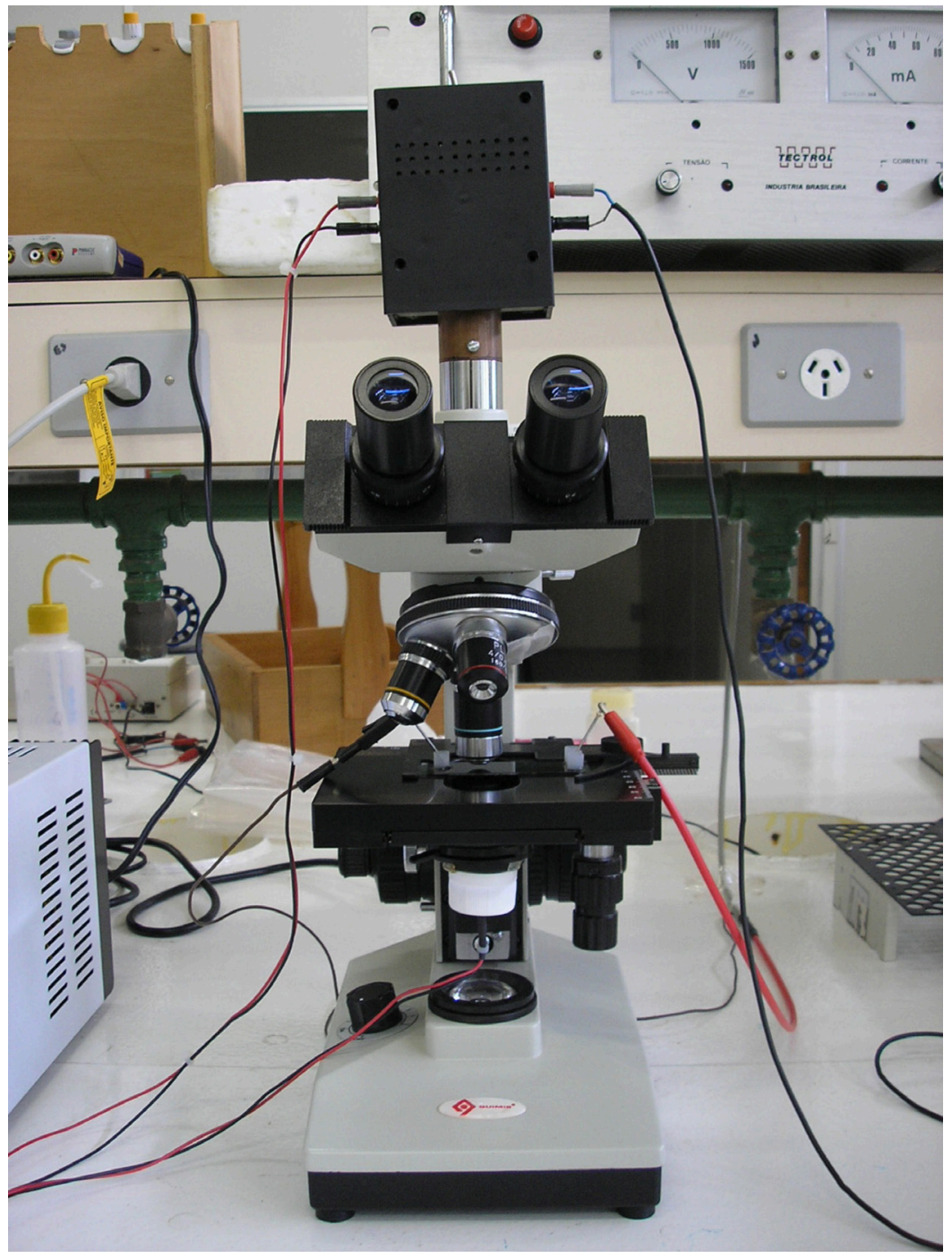

Figure S1. Photograph of the setup used for the photometric EOF monitoring.

*e-mail: fracassi@iqm.unicamp.br 


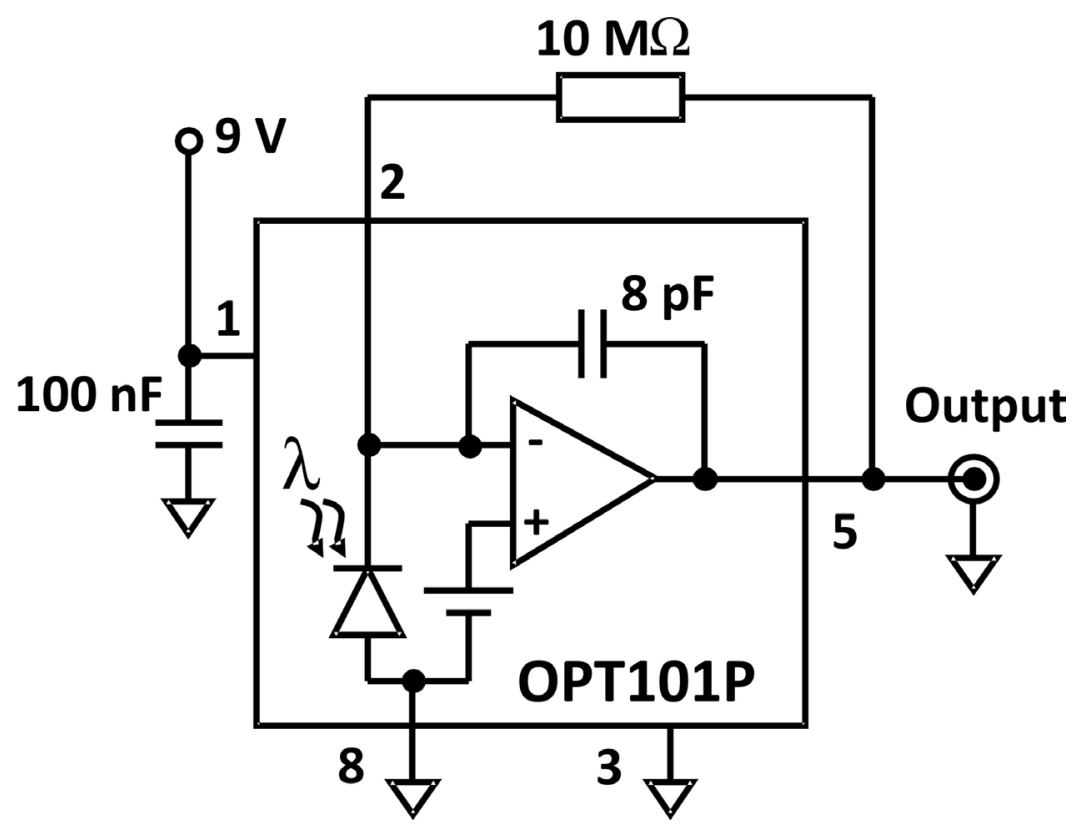

Figure S2. Schematics of the electronic circuit used for the photometric EOF monitoring. The $10 \mathrm{M} \Omega$ resistor connected to pins 2 and 5 can be adjusted for operation in other output scales. 